\title{
Por uma história da esquerda brasileira
}

\section{Maria Paula Nascimento Araújo}

$\mathrm{E}$ leger a esquerda como objeto de estudo me remeteu a uma questáo que é unanimemente vista como delicada pelos historiadores: a paixão. Ou mais claramente, o envolvimento apaixonado com o objeto de estudo.

A decisão de estudar a esquerda, primeiro elegendo-a como meu tema de doutorado e depois, como minha linha de pesquisa prioritária na universidade e no PPGHIS, me colocou frente a esta questão crucial: é possível, para um pesquisador, estudar um objeto pelo qual é apaixonado? Um objeto que fez parte, de forma absolutamente essencial, de sua constituição como um ser adulto e, principalmente, como intelectual e como cidadão?

A primeira vez que esta questão se colocou para mim, eu ingressava no doutorado em Ciências Políticas no IUPERJ e escolhia como objeto de minha tese as novas esquerdas surgidas no Brasil e no mundo, nas décadas de 1960 e 1970 e, especialmente, a esquerda brasileira e seu enfrentamento com o regime militar. ${ }^{1}$ Em suma, escolhia enfocar o período da minha militância política e da minha formação intelectual (dois processos que se deram de forma concomitantes). Nesta época eu me perguntei se esta junção - tão óbvia e tão explícita - era lícita para um pesquisador, sobretudo para um historiador.

O encontro com alguns autores e algumas correntes historiográficas me ajudou a responder a estas dúvidas e promoveu minha definitiva conciliação e conversão ao tema. A escola marxista inglesa, a perspectiva de uma "história vista de baixo", a história política renovada, a História Oral e a História do Tempo Presente foram as correntes que me forneceram os necessários subsídios para a construção do meu tema como um tema relevante e significativo no sentido historiográfico (sem precisar despi-lo de sua dimensão pessoal e passional). 
A perspectiva de trabalhar no sentido da construção de uma história da esquerda brasileira me remeteu, portanto, ao diálogo com estas correntes historiográficas. É este diálogo - teórico e metodológico - que me proponho a reproduzir aqui e compartilhar com outros pesquisadores interessados no tema.

Acho importante esclarecer que a seleção aqui apresentada não se pretende exaustiva nem tem por objetivo mapear o conjunto de abordagens historiográficas referentes ao tema em questão. É uma seleção pessoal e parcial, que reúne os autores e correntes historiográficas que marcaram e influenciaram a minha produção desde que me debrucei sobre o tema da história da esquerda brasileira.

Um dos bons exemplos de que pode ser fecunda e produtiva a ligação entre a militância política e a atividade intelectual e acadêmica foi dado por um grupo de historiadores ingleses vinculados ao Partido Comunista Britânico. Este grupo era composto por nomes que se tornaram, ao longo do século XX, alguns dos mais renomados historiadores ingleses: E.P. Thompson, Eric Hobsbawm, Christopher Hill, Rodney Hilton, George Rudé, Dorothy Thompson, Royden Harrison. Vale lembrar também Maurice Dobb e DonaTorr, já falecidos mas lembrados e respeitados pelo conjunto do grupo, como "precursores".

Este conjunto de historiadores constituía, efetivamente, um "grupo": The Communist Party Historians' Group (o Grupo de Historiadores do Partido Comunista). Este Grupo, que se formou logo após a II Guerra Mundial, no início da Guerra Fria, em torno de 1946, teve enorme influência no desenvolvimento da historiografia marxista e da historiografia inglesa de forma geral. Em 1956, com a divulgação do Relatório Khurshev sobre os crimes de Stalin, muitos intelectuais, e alguns historiadores do Grupo, como Christopher Hill, deixaram o Partido Comunista Britânico. Mas não romperam os laços com o Grupo. Nem com o marxismo. Ao contrário do que sucedeu em outros países - onde o rompimento com o Partido Comunista levou muitos intelectuais a romperem com o marxismo (notadamente na França) - , este grupo de historiadores ingleses manteve os laços de ligação entre eles e com o marxismo. Mais do que isso, o Grupo passou a desenvolver uma visão específica da análise marxista aplicada à História. 
Procurando construir um marxismo não economicista, não determinista, que enfatizava a política, a cultura e a luta de classes como motor da História em detrimento de interpretações exclusivamente centradas no aspecto econômico. Esta postura teórica se expressou numa série de trabalhos históricos que mobilizavam uma enorme massa documental e que significou, como já dissemos, uma grande contribuição tanto para a historiografia inglesa quanto para a historiografia marxista. A partir desta prática do Grupo se criou a referência, conhecida internacionalmente pelos historiadores, da Escola Marxista Inglesa, trazendo a noção de um marxismo diferenciado, não ortodoxo, aplicado à pesquisa histórica. Os historiadores do Grupo trouxeram novas interpretaçôes, novos objetos e novos personagens para a historiografia inglesa.

Rodney Hilton voltou-se para o mundo feudal inglês (The transition of Feudalism to Capitalism) e fez uma nova abordagem dos servos e camponeses, inserindo-os numa relação de luta de classes. Em seu estudo sobre o "Grupo", Gertrude Himmelfarb² salienta que a tese de Hilton representou uma inovação em relação ao marxismo clássico que deprecia e ignora os camponeses como classe. ${ }^{3}$ A luta de classes que a teoria marxista clássica sempre identificou na crise final do feudalismo era aquela que colocava em confronto a aristocracia e a nascente burguesia. Já Hilton traz para o centro da cena o confronto cotidiano entre camponeses e senhores feudais, destaca as revoltas camponesas e aponta esta luta de classes como a principal causa da crise do feudalismo. Com isto dá uma nova dimensão ao campesinato e ao papel da servidão nos estudos sobre o feudalismo. Himmelfarb enfatiza este ponto e afirma que, introduzindo os camponeses feudais na luta de classes, Hilton dotou-os do "atributo histórico essencial de uma classe" e, com isso, tornou-os "dignos de simpatia e respeito". "Hilton também atribuiu aos camponeses uma consciência de classe (mesmo que intermitente, muitas vezes conservadora) mas formada e delimitada por uma "memória" de antigos direitos, costumes e tradiçōes. O que conferia à luta camponesa "dignidade e sentido histórico". 5

Cristhopher Hill tomou para si o tema da Revolução Inglesa. Sua primeira inovação neste campo foi ampliar a dimensão da Guerra Civil Inglesa e transformá-la numa revolução. O sentido da guerra civil teria sido 
o de destruir a ordem feudal e instalar o capitalismo na Inglaterra. A vitória do Parlamento sobre o rei adquiria assim um sentido "direcionador" da história da Inglaterra. Era, efetivamente, uma primeira interpretação marxista dos acontecimentos políticos da história inglesa. Mas a contribuição mais interessante de Hill à historiografia da revolução inglesa talvez seja o livro The world turned upside down, onde analisa as seitas populares radicais que proliferaram durante a revolução inglesa. O livro foi publicado no Brasil com o nome $O$ mundo de ponta cabeça. ${ }^{6}$ Ao escrever este livro, muitos anos após The English Revolution, Hill já havia se afastado de padróes esquemáticos do marxismo (presentes em sua interpretação sobre a revolução inglesa) e conferia maior importância às idéias, práticas e padrões comportamentais. Neste livro Hill focaliza seitas e heresias populares, a "revolta dentro da revolução", a "fascinante torrente de idéias radicais" trazidas por grupos e "fanáticos" que, em sua maioria, foram destruídos pela corrente majoritária e dominante da revolução inglesa. Uma "torrente de idéias radicais" que envolvia, sob o manto da linguagem religiosa, princípios confusos de igualitarismo, comunitarismo e práticas de amor livre. Neste livro Hill afastava-se da ortodoxia marxista e mostrava que era possível um outro caminho para o estudo dos movimentos sociais. Mostrava também que era possível uma outra compreensão da política, na qual personagens marginais, periféricos, anônimos, que nunca tomaram o poder eram vistos como os personagens principais de uma narrativa histórica.

Mas os autores mais importantes da Escola Marxista Inglesa são, efetivamente, Eric Hobsbawm e E. P. Thompson. É baseado neles que muitos dos atuais alunos dos cursos de História desenvolvem suas pesquisas sobre os trabalhadores e sobre movimentos políticos de contestação (sobretudo de orientação marxista), mesmo no Brasil.

A obra máxima de Thompson The making of the Englis working class (publicada pela primeira vez em 1963) talvez seja a obra do "Grupo" que teve maior influência acadêmica. Fundamentalmente por dois motivos: em primeiro lugar, pelo volume e variedade de fontes que foram pesquisadas para a elaboração da obra. Em segundo, pela concepção teórica de "classe" que o livro apresenta, diferente da visão mais comum, divulgada pelo marxismo, que se apóia exclusivamente na dimensão econômica do termo. $\mathrm{Na}$ 
concepção de Thompson, o termo classe vem apoiado numa dimensão histórica, alicerçada em relações sociais, culturais, cotidianas. A dimensão econômica seria apenas uma das referências, mas não seria exclusiva nem mesmo prioritária.

A classe acontece quando alguns homens, como resultado de experiências comuns (herdadas ou partilhadas), sentem e articulam a identidade de seus interesses entre si, e contra outros homens cujos interesses diferem (e geralmente se opõem) dos seus. A experiência de classe é determinada, em grande medida, pelas relações de produção em que os homens nasceram - ou entraram involuntariamente. A consciência de classe é a forma como essas experiências são tratadas em termos culturais:encarnadas em tradições, sistemas de valores, idéias e formas institucionais.?

Para Thompson, a classe não é um dado a priori, não é um conceito estático nem mesmo uma categoria que possa ser depreendida a partir de uma única referência. Para ele, a idéia de classe remete a uma relação histórica, social, cultural. Mas ela é sempre produto de um processo interativo. A classe, para ele, é construção. Esta forma de conceber a idéia de classe social difere bastante do marxismo vulgar para quem a classe era vista, de forma geral, como uma decorrência direta e exclusiva da esfera da produção. Esta nova forma de conceber a questão tinha enorme efeito libertador já que permitia ver, ao lado da posição econômica, uma série de outros aspectos - a cultura, a arte, as práticas cotidianas, as relaçôes de sociabilidade, de vizinhança, os embates políticos diários, as opçōes pessoais, a produção artística, os laços de solidariedade construídos, enfim, uma gama de aspectos que iam muito além da mera posição econômica.

A fonte de inspiração para este conceito de classe, assumida pelo próprio Thompson, é o marxismo de Gramsci. A teoria gramsciana, esboçada principalmente no livro Os intelectuais e a organização da cultura, ${ }^{8}$ já apontava para um marxismo distante dos reducionismos economicistas e já valorizava o processo histórico, os aspectos culturais, as interações sociais e, sobretudo, a luta política como elemento definidor central (muito superior à posição na esfera produtiva). Este marxismo permeado de historicidade, de cultura e de política, da idéia de processo, de construção e de interação social traça uma linha (não necessariamente reta) de ligação entre 
o pensamento de Gramsci e a obra de Thompson. Tanto para um como para outro, a classe é construída num processo histórico, marcado por opções políticas tomadas por sujeitos que são artífices atuantes de seus próprios destinos.

O outro grande historiador do "Grupo" - e provavelmente o mais famoso internacionalmente, inclusive fora do circuito acadêmico, é Eric Hobsbawm. Não é meu objetivo aqui, neste pequeno artigo, analisar a vastíssima obra deste autor, mas apenas destacar a sua importância como referência para uma história dos movimentos e das idéias de esquerda.

Os livros de Hobsbawan foram campeões de venda, lidos não apenas por professores e estudantes de história de todos os países mas também por um público inteiramente leigo. No Brasil, onde foi publicado primeiro pela editora Paz e Terra e, depois, pela Companhia das Letras, seus livros tiveram enorme repercussão. A era do capital, $A$ era das revoluções, $A$ era dos extremos, Revolucionários, Os trabalhadores, Sobre História e a portentosa coleção por ele organizada, História do Marxismo, entre outros títulos, tiveram ampla aceitação e circulação entre leitores brasileiros, ao longo das décadas de 1970, 80 e 90.

Embora tenha escrito sobre vários assuntos (inclusive sobre o jazz) Hobsbawm desenvolveu dois grandes temas: os trabalhadores e os movimentos de esquerda (com ênfase nos movimentos de orientação marxista mas não apenas). É o historiador que mais nos fornece elementos para pensarmos a esquerda (ou, melhor dizendo, as esquerdas, no sentido o mais plural possível) como um fenômeno histórico de grande relevância não apenas política, mas também social.

Em tempos atuais - após o fracasso das experiências socialistas no mundo, após a queda do Muro de Berlim e a derrocada da União Soviética, após a crise política do projeto socialista que se desdobrou na crise teórica do marxismo - pode parecer que a produção intelectual deste grupo de historiadores tão fortemente marcada pela militância política e pela orientação teórica marxista esteja superada. Ou que o caráter explicitamente engajado dos autores e de suas obras confira ao grupo uma dimensão excessivamente "datada". Quanto a este último ponto não há dúvida: a pro- 
dução dos historiadores da Escola Marxista Inglesa é efetivamente "datada". Mas no sentido em que todo texto é "datado", ou seja, inserido num determinado contexto histórico filosófico e político. E não por ser engajada politicamente. Aliás, este engajamento é, ele próprio, uma das características de seu contexto, de um momento - ao longo das décadas de 1950, 60 e 70 - de um acirrado debate intelectual marcado pelo confronto de idéias e de projetos políticos: a "batalha das idéias" ("the battle of ideas") na expressão de Hobsbawm. A Escola Marxista Inglesa participou desta batalha. Mas longe de ter permanecido no terreno vazio da propaganda, do doutrinarismo e do proselitismo, marcou de forma significativa a historiografia inglesa: reinterpretando momentos clássicos da História da Inglaterra, criando novos temas e novos personagens para esta História, elaborando novas categorias de análise, lançando luzes surpreendentes sobre diversos episódios e levantando uma volumosa massa documental. Os historiadores do "Grupo" elegeram alguns momentos-chave para a pesquisa, que traziam consigo a construção de temas privilegiados — a transição do feudalismo para o capitalismo, a Revolução Inglesa, as seitas religiosas radicais, a formação da classe trabalhadora, os bandidos, os rebeldes, os trabalhadores, os militantes políticos, as idéias socialistas. A escola marxista inglesa deu consistência e sentido histórico à experiência de massas anônimas, de personagens marginais, periféricos, outsiders, "fanáticos" (Hilton e Hill), ao processo de organização social e política dos trabalhadores (Thompson), ao debate das idéias políticas contestadoras (Hobsbawm). E sobretudo, mostrou que é possível e importante recuperar e narrar a história das lutas dos povos através de seus movimentos sociais e de suas variadas formas de organização e expressão política. Mostrou também que as idéias e propostas produzidas por muitos destes movimentos, por mais "visionárias" e "fanáticas" que possam parecer às geraçōes posteriores, dizem muito da sociedade em que brotaram (Hill). Mais do que isso: a Escola Inglesa ensinou a importância da "batalha das idéias"; a necessidade de se reservar, na narrativa histórica, um espaço de destaque para as concepções políticas e ideológicas, os valores culturais, as práticas políticas e cotidianas, os debates teóricos, os confrontos entre diferentes proposições, tanto as gerais quanto as particulares. Somente com esta perspectiva a História — e sobretudo a História Política — ganha corpo, forma, alma, cor e voz. 
Uma outra corrente que valorizava a luta cotidiana dos povos, enfocando principalmente as classes populares, é a chamada "história vista de baixo" - que, em certo sentido, é um produto da Escola Marxista Inglesa. A expressão "history from below" foi criada por E. P. Thompson num artigo publicado em 1966 no suplemento literário do The Times.

Num artigo já clássico para professores e estudantes de História, Jim Sharp9 nos dá uma bela definição da "história vista de baixo", a partir da correspondência do soldado William Wheeler, da 51ํㅡㄹ Infantaria Britânica que lutou na batalha de Waterloo. As cartas de Wheeler para sua esposa relatam a batalha do ponto de vista do soldado raso: “(...) a experiência de suportar o fogo da artilharia francesa, seu regimento destruindo um corpo de couraceiros inimigos com uma rajada de tiros, o espetáculo de montes de corpos queimados de soldados britânicos nas ruínas do castelo de Hougoumont, o dinheiro saqueado de um oficial hussardo francês, alvejado por um membro do destacamento a cargo de Wheeler". ${ }^{10}$

Jim Sharp afirma que nas últimas décadas vários historiadores, em vários países, sentiram-se tentados a explorar o potencial deste tipo de fonte e narrar a história "do ponto de vista do soldado raso e não do grande comandante". Mas Sharp também aponta que a "história vista de baixo" traz alguns problemas teóricos que ainda estão longe de serem solucionados. Entre eles o mais delicado talvez seja a definição de cultura popular. Assim como a História Oral traz o questionamento em torno do tema da memória (como veremos mais adiante), a "história vista de baixo" traz o tema da cultura popular. E este tema, no cruzamento do debate entre historiadores, antropólogos, sociólogos, folcloristas e críticos de arte - está longe de ser resolvido. Em seu artigo, Sharp discute a abordagem da cultura popular no início da era moderna, através principalmente dos estudos de Le Roy Ladurie e de Carlo Ginzburg.

Nosso objeto de estudo - práticas e representações de grupos, movimentos, partidos e organizaçóes de esquerda - se situa no mundo contemporâneo. No entanto, a tese da "circularidade cultural" desenvolvida por Ginzburg no livro $O$ queijo e os vermes, ${ }^{11}$ pode nos ser bastante útil como ferramenta de trabalho. Inspirado na obra de Bakhtin sobre Rabelais e a cultura popular renascentista, ${ }^{12}$ Ginzburg afirma a tese de um movi- 
mento circular constante entre a cultura erudita e a cultura popular. Bakthine salientara o fato de que a prosa de Rabelais se nutria das manifestaçôes populares renascentistas, da cultura cômica popular. E que esta cultura, por sua vez, promovia uma paródia da cultura de elite. Um movimento, portanto, de troca constante, de "circularidade" permanente, de interpenetração e interferência mútua, no dizer de Ginzburg. O historiador que se volta para estudar os movimentos populares de contestação no mundo contemporâneo deve estar atento para esta circularidade, para esta interpenetração de elementos culturais diversos que vão da elite para as camadas populares e vice-versa.

A contribuição de Gramsci neste sentido também é fundamental. ${ }^{13}$ A discussão em torno dos movimentos de esquerda e de contestação nas sociedades contemporâneas, numa visão gramsciana, deve necessariamente levar em conta a questão da cultura. Para Gramsci a cultura está no cerne da luta política. O conceito gramsciano chave para o entendimento da política é o conceito de hegemonia: a idéia de que a política não se exerce apenas, nem prioritariamente, pela força, mas sim pelo consenso; pelo compartilhamento de valores, visões de mundo, conceitos éticos e morais e padrões comportamentais. Ou seja, a cultura é um instrumento de força política. É ela — a cultura compartilhada — que sedimenta e possibilita a hegemonia de um grupo sobre o conjunto da sociedade.

Dessa forma, a relação de circularidade entre cultura popular e cultura erudita seria também uma relação de conflito, de disputa. Circularidade sim, mas não isenta de choques, de conflitos. $\mathrm{O}$ terreno da cultura para Gramsci é um terreno de luta política, de disputa por valores, visões de mundo, conceitos éticos e padrões de comportamento. É no terreno da cultura que os diferentes grupos sociais disputam a hegemonia. Se a cultura não é o espaço essencial desta disputa é, sem dúvida, um dos mais importantes. Assim, uma história da esquerda brasileira teria que levar necessariamente em conta este campo de disputas e conflitos e entender as posturas, práticas, imagens e representações produzidas pela esquerda como frutos deste processo.

Um outro grupo de correntes historiográficas, desenvolvidas nos últimos anos, vem contribuindo para a valorização de pesquisas sobre movi- 
mentos, partidos, idéias, experiências e personagens da esquerda contemporânea. Deste grupo fazem parte a História Oral, o estudo de trajetórias de vida, a História do Tempo Presente e o que se convencionou chamar de "história política renovada".

\section{A História Oral e "histórias de vida"}

Os historiadores, nas últimas décadas, têm se utilizado, em larga medida, de determinados procedimentos de pesquisa que antes lhes eram, de certa forma, vedados: entrevistas, relatos autobiográficos, depoimentos pessoais, histórias de vida etc. Estas técnicas de pesquisa, até os anos 1970, eram recursos específicos de antropólogos em seus trabalhos de campo. Nos últimos anos, no entanto, elas têm contribuído, indistintamente, para historiadores, sociólogos, antropólogos, cientistas políticos e outros pesquisadores criando um campo interdisciplinar. Um campo fecundo que busca compreender o homem em sua dimensão social e histórica a partir de seu relato vivo, sua memória e sua oralidade.

Se antropólogos e sociólogos já estavam mais afeitos a estas técnicas, elas significaram, para o historiador, uma grande novidade. Acostumados a trabalhar com os "mortos" e seus registros, os historiadores passaram a poder trabalhar com os "vivos". E a organizar, para a posteridade, os registros destes personagens ainda vivos — na forma de gravações de entrevistas e depoimentos. Um novo tipo de acervo começou a ser criado nas universidades e centros de estudos históricos: os acervos de História Oral. ${ }^{14}$

A História Oral se cruza, muito freqüentemente, com as histórias de vida, com as análises de trajetórias e com as biografias coletivas. O casamento entre História Oral e histórias de vida vem se mostrando dos mais fecundos para a pesquisa histórica. Ele permite a valorização da oralidade como fonte, como registro e como linguagem - com o mesmo status da linguagem escrita. Ele permite um mergulho na vida cotidiana e privada das pessoas do grupo ou da comunidade estudada, tornando possível, ao historiador, estabelecer uma relação entre a História e os caminhos de vida de pessoas reais num determinado momento, num dado lugar. É importante lembrar, no entanto, que a "história de vida" apresenta algumas ar- 
madilhas para o pesquisador que a utiliza como fonte e narrativa. Bourdieu faz este alerta num artigo intitulado, muito à propósito, "A ilusão biográfica" ${ }^{15}$ A entrevista que recompõe a história de vida ("récit de vie") organiza a vida como uma história, segundo uma ordem cronológica, com princípio, meio e fim bem definidos e, quase sempre, com um sentido, um objetivo claro. Ora, as vidas humanas raramente têm esta organização, este sentido claro, esta racionalidade. "Produzir uma história de vida, tratar a vida como uma história, isto é, como o relato coerente de uma seqüência de acontecimentos com significado e direção, talvez seja conformar-se com uma ilusão retórica." Para escapar desta ilusão, Bourdieu propõe a noção de trajetória, "como uma série de posições sucessivamente ocupadas por um mesmo agente (ou um mesmo grupo) num espaço que é ele próprio um devir, estando sujeito a incessantes transformaçôes". Ou seja, uma trajetória (noção que substituiria a idéia de "história de vida") só pode ser compreendida a partir de um quadro de interaçóes sociais. A trajetória de um indivíduo é avaliada a partir do confronto com outros indivíduos num determinado momento e contexto (o conceito de "campo" em Bourdieu).

Apesar das armadilhas apontadas por Bourdieu, é inegável a ampliação de horizontes da pesquisa histórica produzida pela História Oral. Paul Thompson, em seu livro $A$ voz do passado, sugere que "no sentido mais geral, uma vez que a experiência de vida das pessoas de todo tipo possa ser utilizada como matéria-prima, a história ganha nova dimensão". ${ }^{16}$

Um outro caminho para fugir das armadilhas apontadas por Bourdieu é a metodologia proposta por Franco Ferrarotti em seu livro Histoire et histoires de vie — La méthode biographique dans les sciences sociales. ${ }^{17} \mathrm{No}$ prefácio à edição francesa, Georges Balandier chama a atenção para algumas das características mais interessantes do trabalho de Ferrarotti: a relação entre a história e as múltiplas histórias individuais e a possibilidade que daí decorre de "ler uma sociedade através de uma biografia". O livro de Ferrarotti se propõe a dar uma base teórica ao método biográfico, mas o utiliza no plural. De uma forma geral, nos diz ele, o método biográfico é utilizado para um indivíduo, para elaboração de biografias individuais. Esta escolha esconderia um equívoco: a idéia do indivíduo como átomo social, unidade básica fundamental da sociologia. Na verdade o indivíduo não é 
este elemento mais simples. Ao contrário, o indivíduo enquanto tal é uma síntese complexa de várias relações. A unidade mais básica da sociologia seria, então, o grupo social — um grupo básico que estabelecesse, entre si, relações de sociabilidade, de troca, de interação. Seu método de histórias de vida volta-se, portanto, para a construção de biografias de grupo. É desta forma que ele apresenta sua maior riqueza e seu maior potencial: ao mostrar que as múltiplas histórias de vida particulares de uma época, de uma geração, de um lugar, se inscrevem dentro dos limites e das possibilidades de uma História mais geral — e que cada uma dessas múltiplas histórias particulares interpreta, a seu jeito, a História e sua relação com ela. História e histórias de vida: é esta relação que emerge do método proposto por Franco Ferrarotti. E é nesta perspectiva que organizamos nosso acervo de entrevistas e depoimentos intitulado "Memórias de Esquerda" (mais adiante, neste artigo, daremos mais detalhes sobre este acervo).

\section{Uma História do Tempo Presente}

Assim como a barreira em relação às fontes orais foi vencida, uma outra barreira foi superada pelos historiadores nos últimos anos: a da contemporaneidade. Em certa medida, estas duas questôes (contemporaneidade e fontes orais) estão relacionadas: a reintegração do tempo presente na História valoriza o testemunho direto, o depoimento da experiência pessoal, o resgate da memória individual e coletiva em torno de episódios históricos.

O impulso fundamental para a história do tempo presente foi dado por um grupo de historiadores franceses que se reuniram no Instituto de História do Tempo Presente de Paris - um laboratório de estudos e pesquisas criado pelo CNRS, dirigido por François Bédarida. Em torno do Instituto pesquisadores como René Rémond, Roger Chartier, Henri Rousseau começaram a desenvolver pesquisas em torno das últimas décadas do século XX. Estes historiadores ajudaram a construir a necessária justificativa teórica para a história do tempo presente, fazendo com que elementos que na perspectiva de uma historiografia tradicional eram vistos como problemáticos passassem a ser vistos como positivos: a proximidade temporal e o envolvimento pessoal. Chartier afirma que, em vez de representarem problemas, eles podem redundar em vantagens. $\mathrm{O}$ historia- 
dor do tempo presente "contemporâneo ao seu objeto, partilha com aqueles cuja história ele narra as mesmas categorias essenciais, as mesmas referências fundamentais", ${ }^{18}$ podendo portanto superar a descontinuidade que costuma existir entre o universo intelectual, afetivo e psíquico do historiador e dos homens e das mulheres cujas vidas ele narra, escapando do perigo do anacronismo.

Alem disso, a história do tempo presente representa o último golpe numa concepção historiográfica sedimentada na idéia de imparcialidade, pura objetividade, narrativa distanciada; ou seja, na crença "positivista" de uma história isenta de subjetividade. A história do tempo presente reconhece o historiador comprometido com seu tempo, com as questóes do seu tempo. Reconhece seu engajamento pessoal, sua paixão. E justamente por isso torna crucial a questão da verdade. Não uma verdade pretensamente objetiva e imparcial (e por isso "científica"). Mas a busca da verdade como compromisso ético moral do historiador. Ele sabe que a verdade "total", pura, cristalina é impossível de ser atingida. O historiador chega a "retalhos" de verdade, pedaços parciais. Mas a busca por esta verdade — que ele sabe que, de certa forma, nunca será atingida - é o que o move e o faz estar atento a qualquer forma de manipulação da narrativa histórica. Não apenas do passado, mas também do presente.

A motivação inicial da história do tempo presente (que, em muitos aspectos, também se verificou em relação à história oral) foi a necessidade de resgatar para a História algumas experiências ainda recentes, extremamente importantes, mas com pouca documentação disponível. Urgia criar e organizar a documentação referente a estas experiências, que necessariamente não passariam por registros oficiais. Entre outras, uma boa parte da experiência histórica da II Guerra Mundial relativa ao holocausto, à resistência antifascista, às vivências de grupos minoritários (como ciganos e homossexuais). Assim como também (e neste aspecto a História do Tempo Presente se vinculou à perspectiva da "história vista de baixo"), a necessidade de registrar a experiência histórica dos trabalhadores em seus movimentos grevistas ou comunitários.

No Brasil - e na América Latina de forma geral — um dos grandes temas da história do tempo presente tem sido o estudo das ditaduras mi- 
litares no continente, na segunda metade do século XX: as diversas formas de repressão política, a experiência das esquerdas e das lutas populares de resistência, os processos de redemocratização e as diferentes experiências de reconstrução da institucionalidade democrática nestes países.

\section{A história política renovada}

Durante muitos anos, a história política foi identificada como "factual, subjetivista, psicologizante, idealista" ${ }^{19}$ Centrada nos grandes nomes, nos grandes eventos, tecida em torno de fatos e datas. Na historiografia inglesa a recuperação da história política se deu, como já discutimos neste artigo, através do empenho da Escola Marxista Inglesa que incorporou o tema das massas, das seitas populares, dos camponeses, dos trabalhadores, dos movimentos de esquerda e do marxismo, produzindo uma história política muito distante do paradigma rankeano. ${ }^{20}$

$\mathrm{Na}$ historiografia francesa esta recuperação se deu através de um grupo de historiadores que encetou um movimento intelectual de valorização e resgate da história política. À frente do grupo, René Rémond. A obra que é praticamente o manifesto do grupo se chama, justamente, "Por uma História Política". Para Rémond, o vigoroso retorno da história política nas últimas décadas teria relação com algumas características do cenário internacional contemporâneo: a experiência das guerras, a pressão das relações internacionais, o desenvolvimento das políticas públicas sugerindo uma nova relação entre economia e política, as discussões em torno das atribuições do Estado, as demandas da opinião pública - tudo isso teria contribuído para "dar crédito à idéia de que o político tinha uma consistência própria e dispunha mesmo de uma certa autonomia em relação aos outros componentes da realidade social". ${ }^{21}$

Para René Rémond, esta nova história política trazia consigo novos temas e novos objetos: eleiçôes e comportamento eleitoral, mídia, opinião pública, intelectuais, a relação entre religião e política, partidos e associações. Esta história política renovada teria também, como característica essencial, a interdisciplinaridade.

De fato, a renovação da história política foi grandemente estimulada pelo contato com outras ciências sociais e pelas trocas com outras disciplinas. 
(...) É impossível para a história política praticar o isolamento: ciência encruzilhada, a pluridisciplinaridade é para ela como o ar de que ela precisa para respirar. ${ }^{22}$

É no interior do campo teórico e metodológico criado pelo cruzamento destas diferentes correntes historiográficas que se situa a história da esquerda brasileira. Valorizada pela perspectiva da História do Tempo Presente, tendo como tema principal a resistência à ditadura militar levada a cabo por movimentos populares e grupos e partidos clandestinos de esquer$\mathrm{da}$; recolhendo depoimentos e organizando acervos orais com entrevistas e testemunhos de militantes políticos; trabalhando com disciplinas afins como a sociologia e a ciência política; recuperando a experiência de grupos radicais e extremistas; resgatando idéias e propostas de partidos e organizaçôes, de movimentos alternativos como o movimento feminista e os movimentos negros; recuperando imagens e representações destes grupos; levantando uma volumosa massa documental que inclui publicações da chamada "imprensa alternativa", jornais clandestinos, panfletos; levantando a memória de militantes de uma série de partidos e organizações políticas que viveram praticamente toda a sua existência em regime de clandestinidade; revelando trajetórias de vida e biografias fortemente marcadas pelo confronto com a repressão e a violência do regime militar.

É nesse sentido que tenho desenvolvido, nos últimos anos, uma pesquisa sobre a história da esquerda brasileira, especialmente centrada na experiência de resistência ao regime militar e no processo de redemocratização do país (entre as décadas de 1960, 70 e 80).

A literatura sobre a esquerda no Brasil já é bastante vasta e variada. Pesquisadores ligados a diferentes tradições e com abordagens distintas vêm produzindo dissertações, teses e obras sobre o tema. ${ }^{23}$ Não caberia aqui neste artigo fazer uma ampla apreciação desta bibliografia mas gostaria de destacar alguns autores e algumas obras que considero importantes para o desenvolvimento deste campo de estudos.

Daniel Aarão Reis é um dos historiadores que tem contribuído sobretudo para a história da esquerda brasileira durante o período do regime militar. Junto com Jair Ferreira de Sá, antigo dirigente da organização de esquerda Ação Popular Marxista Leninista (APML), já falecido, compilou 
documentos de quase todas as organizações de esquerda, entre 1960 e 1970, produzindo um livro que também pode ser utilizado como instrumento de pesquisa: Imagens da revolução: documentos políticos das organizaçôes clandestinas de esquerda dos anos 1961-1971. ${ }^{24}$ Cabe lembrar também o belo livro escrito em colaboração com Pedro de Moraes, 1968: a paixão de uma utopia, ${ }^{25}$ e, da coleção "Descobrindo o Brasil" o livro Ditadura militar, esquerdas e sociedade. ${ }^{26}$

Outro historiador que se constitui como referência inquestionável para o estudo da esquerda brasileira é Jacob Gorender. Seu livro Combate nas trevas $^{27}$ é obra obrigatória para todos que desejam se aprofundar neste tema. Com farto material fotográfico e amplo conhecimento do assunto, inclusive por sua nunca escondida vinculação e militância política, o livro de Gorender tornou-se um clássico para estudantes e pesquisadores interessados sobretudo na história da luta armada.

Nos últimos anos a história oral tem produzido importantes trabalhos sobre o tema, que recuperam a memória de antigos militantes. Como o livro de Dulce Pandolfi Camaradas e companheiros: história e memória do $P C B^{28}$ e o livro de Alzira Abreu Intelectuais e guerreiros, ${ }^{29}$ sobre militantes estudantis do Colégio de Aplicação. É interessante destacar a abordagem de gênero feita por Elizabeth Xavier Ferreira no livro Mulheres, militância e memória ${ }^{30}$ no qual a autora trabalha com a memória especificamente feminina da experiência da militância, da prisão e da tortura durante os anos de resistência ao regime militar.

No campo da ciência política, Emir Sader é outro autor voltado para o estudo da esquerda brasileira. Seu livro $O$ anjo torto: esquerda (e direita) no rrasil $^{31}$ é uma boa iniciação para os interessados no tema. Sobre idéias e práticas marxistas, enfocando principalmente o debate em torno das concepções de esquerda, no Brasil e na América Latina, cabe citar o livro organizado por Michel Lowy, O marxismo na América Latina ${ }^{32}$ e a obra de João Quartin História do Marxismo no Brasil. ${ }^{33}$

Sobre o Partido Comunista Brasileiro, um livro recente, extremamente interessante, faz uma discussão sobre a trajetória do PCB e de sua constante oscilação entre posturas mais "stalinistas" ou conciliadoras: A esquerda positiva: as duas almas do Partido Comunista (1920-1964), de Gildo 
Brandão. ${ }^{34}$ Vale lembrar ainda a vasta obra memorialística de antigos militantes do "Partidão", como Gregório Bezerra e Otávio Brandão. ${ }^{35}$

A luta armada também possui uma variada crônica de relatos autobiográficos e de obras literárias, sobretudo romances. Além dos bem conhecidos O que é isso, companheiro?, de Fernando Gabeira, e Os carbonários, de Sirkys, há um romance que, na minha opinião, merece destaque pela qualidade literária e dimensão dramática: Em câmera lenta, de Renato Tapajós, ${ }^{36}$ lamentavelmente esgotado.

De forma geral, a literatura sobre a esquerda brasileira tem privilegiado dois tema: a história do PCB e a luta armada. A experiência dos anos 1970 e 80 - da resistência à ditadura e do processo de redemocratização — ainda é muito pouco abordada. E é este, exatamente, o meu objeto de estudo.

Nos últimos anos tenho procurado contribuir para uma história da esquerda brasileira enfocando justamente alguns aspectos que ainda não têm sido, a meu ver, devidamente contemplados. Em especial, grupos, partidos e organizações de esquerda independentes e/ou dissidentes do PCB, uma esquerda por muitos considerada "extremista", "radical” e por ela própria auto-intitulada como "alternativa" ou "revolucionária”; movimentos de minorias políticas (feministas, homossexuais, negros, índios); movimentos populares como movimentos de bairros e movimentos estudantis; experiências culturais (como grupos de arte, teatro, dança e música das favelas cariocas). O objetivo da pesquisa é o resgate de uma determinada experiência política, recuperando e analisando práticas e representações, idéias, propostas, visões de mundo, concepções e imagens, padrões comportamentais, proposições táticas e estratégicas, experiências e vivências cotidianas, relações de sociabilidade, crenças e valores éticos morais.

Esta pesquisa se desenvolve em torno da organização de dois acervos documentais: um acervo de imprensa alternativa e um acervo de História Oral intitulado "Memórias de Esquerda". Os dois acervos estão ativos e aglutinam em volta deles estudantes realizando pesquisas sobre a história da esquerda brasileira. $\mathrm{O}$ acervo de imprensa alternativa reúne diferentes publicações da década de 1970 como os jornais Opinião, Movimento, Em Tempo, Voz da Unidade, O Companheiro, Versus, jornais do movimento 
negro (como Sinba, Nego). Reúne também panfletos e documentação de partidos e organizações clandestinas do período. O acervo "Memórias de Esquerda" reúne entrevistas e depoimentos de militantes e lideranças de partidos, organizações e movimentos de esquerda e de oposição de forma geral. Seguindo a metodologia de Ferrarotti, já comentada, procuramos organizar blocos de depoimentos que congreguem pessoas vinculadas entre si a partir de alguma proposta política. Por exemplo: jornalistas da imprensa alternativa, militantes de organizaçóes de esquerda, militantes do movimento negro, padres e militantes da esquerda católica, mulheres feministas, mulheres da luta armada, lideranças estudantis etc.

Para seleção, realização e análise das entrevistas temos duas questões principais (dois problemas) a nortear nosso trabalho: em primeiro lugar, quais as estratégias de resistência que a sociedade, sobretudo as forças de esquerda e de oposição, conseguem criar para enfrentar um regime de arbítrio e de ausência de democracia? Em segundo lugar, quais as possibilidades existenciais de uma geração que ingressou na vida adulta durante $o$ regime militar? Quais as escolhas possíveis, como estas escolhas foram vividas, qual o impacto de determinadas experiências-limite como a prisão, a tortura, o exílio na vida destas pessoas?

A primeira questão remete a uma problemática essencialmente política, ensejando uma reflexão sobre as condições de exercício da cidadania fora do contexto democrático. É uma investigação também sobre a criatividade política da sociedade civil frente a conjunturas adversas. A segunda remete a um campo bastante novo de investigação que tem por objeto central o trauma. Em recentes encontros internacionais de História Oral esta questão tem surgido em diferentes contextos. A preocupação é verificar como indivíduos e grupos sociais enfrentam tragédias naturais e políticas. Pesquisas desta ordem foram realizadas, por exemplo, na África do Sul, recompondo dramáticas experiências do regime do aparthaid. É um campo de investigação novo no qual a história se cruza, de forma ainda pouco usual, com a psicologia.

De uma forma geral — e sem ter a vã pretensão de esgotar o tema estes são os elementos gerais que norteiam, a meu ver, uma discussão sobre a história da esquerda brasileira. Uma história onde ainda há muito por 
fazer, isto é, muitos arquivos a serem levantados, muitas questões a serem definidas, muitos temas a serem trabalhados, muitos fantasmas a serem superados, muitos pontos a serem esclarecidos, mas também inúmeras e belas experiências a serem resgatadas para as futuras geraçôes.

Porque, afinal de contas, a história da esquerda — no Brasil e no mundo - é também a história de uma paixão. Uma paixão capaz de mover homens e mulheres na tentativa de mudança e de transformação das sociedades em que vivem.

\section{Notas}

${ }^{1}$ Esta tese foi publicada com o título A Utopia Fragmentada: as novas esquerdas no Brasile no Mundo na década de 1970. Rio de Janeiro: FGV, 2000.

${ }^{2}$ Himmelfarb, Gertrude. The "Group": British Marxist Historians. The New History and the Old. Harvard College, 1987.

${ }^{3}$ Para aprofundamento deste assunto veja o artigo de minha autoria "A questão camponesa na teoria marxista clássica" In Chevitarese, André (Org.). O campesinato na História. Rio de Janeiro: Relume-Dumará; FAPERJ, 2002.

${ }^{4}$ Himmelfarb, Gertrude. Op.cit. p 77.

${ }^{5}$ Idem.

${ }^{6}$ Hill, C. O mundo de ponta cabeça. São Paulo: Companhia das Letras, 1987.

${ }^{7}$ Thompson, E. P. A formação da classe operária inglesa. Rio de Janeiro: Paz e Terra, 1987. Vol I, p. 10.

${ }^{8}$ Gramsci, Antônio. Os intelectuais e a organização da cultura. Civilização Brasileira: Rio de Janeiro, 1982.

${ }^{9}$ Sharp, Jim. A História vista de baixo. In Burke, Peter (Org.). A escrita da História. São Paulo: UNESP, 1992.

${ }^{10}$ Idem. p. 40.

${ }^{11}$ Ginzburg, Carlo. O queijo e os vermes. São Paulo: Companhia das Letras, 1998.

${ }^{12}$ Bakhtin, Mikhail. A cultura popular na Idade Média e no Renascimento. São Paulo: HUCITEC, 1993.

${ }^{13}$ Para esta discussão ver a obra de Gramsci já citada.

${ }^{14}$ No Brasil, o Centro de Pesquisa e Documentação da Fundação Getulio Vargas (CPDOC/ FGV) foi pioneiro neste trabalho criando, na década de 1970, um setor de História Oral. A partir daí, outros centros deste tipo têm sido criados junto a universidades e instituiçôes de pesquisa: arquivos de memória, acervos de entrevistas etc. Um tipo de documentação que se expressa na oralidade e que se registra pela fita de gravador (mais recentemente, 
também, pela fita de vídeo). Nossa linha de pesquisa vem organizando o acervo "Memórias de Esquerda”.

${ }^{15}$ Bourdieu, Pierre. Lillusion biographique. Actes de la Recherche en Sciences Sociales, juin, 1986. Reproduzido no livro Usos e abusos da História Oral, já citado.

16 Thompson, Paul. A voz do passado. Rio de Janeiro: Paz e Terra, 1992. Neste livro Thompson faz uma avaliação do uso das fontes orais pelo historiador.

${ }^{17}$ Ferrarotti, Franco. Histoire et histoires de vie — la méthode biographique dans les sciences sociales. Paris: Librairie des Meridiens, 1983.

${ }^{18}$ Ferreira, Marieta e Amado, Janaína. Usos e abusos da História Oral. Rio de Janeiro: FGV, 1996

${ }^{19}$ Rémond, René. Por uma História Política. Rio de Janeiro: UFRJ/FGV, 1996. p. 18.

${ }^{20}$ Por "paradigma rankeano" entende-se o paradigma tradicional da história desenvolvido e sintetizado por Leopold von Ranke: a história como uma visão "de cima”: os grandes feitos de grandes homens; o estudo da vida de monarcas, estadistas, generais e sempre baseada em documentos escritos.

${ }^{21}$ Rémond, René Op.cit. p. 23.

${ }^{22}$ Idem. p. 29.

${ }^{23} \mathrm{O}$ site organizado por Ricardo Figueiredo de Castro (IFCS/UFRJ), Guia da História da esquerda brasileira apresenta um panorama geral do que existe em termos de bibliografia, acervos, documentos e trabalhos recentemente publicados sobre o tema. O site pode ser acessado através da página do IFCS.

${ }^{24}$ Reis, Daniel Aarão, Sá, Jair Ferreira de. Imagens da Revolução. Rio de Janeiro: Marco Zero, 1985.

${ }^{25}$ Reis, Daniel Aarão, Moraes, Pedro de. 1968: A paixão de uma utopia. Rio de Janeiro: Espaço e Tempo, 1988.

${ }^{26}$ Reis, Daniel Aarão. Ditadura militar, esquerdas e sociedade. Rio de Janeiro: Jorge Zahar Editor, 2000.

${ }^{27}$ Gorender, Jacob. Combate nas trevas, São Paulo: Ática, 1987.

${ }^{28}$ Pandolfi, Dulce. Camaradas e companheiros. Rio de Janeiro: Relume-Dumará, 1995.

${ }^{29}$ Abreu, Alzira. Intelectuais e guerreiros. Rio de Janeiro: UFRJ, 1992.

${ }^{30}$ Ferreira, Elizabeth Xavier. Mulheres, militância e memória. Rio de Janeiro: FGV, 1996.

${ }^{31}$ Sader, Emir. $O$ anjo torto. São Paulo: Brasiliense, 1995.

32 Lowy, Michel (Org.). O marxismo na América Latina. São Paulo: Fundação Perseu Abramo, 1999.

${ }^{33}$ Quartim, João. História do marxismo no Brasil. São Paulo: Unicamp, 1998.

${ }^{34}$ Brandão, Gildo Marçal. A esquerda positiva. São Paulo: Hucitec, 1997.

${ }^{35}$ De Bezerra veja o segundo volume de Memórias. São Paulo: Civilização Brasileira, 1979 e de de Otávio Brandão o livro Combates e batalhas. São Paulo: Alfa-Ômega, 1978.

36 Tapajós, Renato. Em câmera lenta. São Paulo: Alfa-Ômega, 1977. 


\section{Resumo}

$O$ artigo discute o campo teórico e historiográfico no qual se pode inserir uma história da esquerda brasileira. Este campo pode ser teoricamente formulado a partir das contribuiçôes de algumas correntes historiográficas contemporâneas. Entre elas: a Escola Marxista Inglesa, a "história vista de baixo", a História Oral, a história do tempo presente, e a história politica renovada. No Brasil tem crescido o número de trabalhos voltados para a história da esquerda brasileira. A maior parte desta literatura enfoca a história do PCB e a luta armada. Operiodo compreendido entre as décadas de 1970 $e 80$, caracterizado essencialmente pela resistência e pelo processo de redemocratização, ainda não foi suficientemente estudado.

\section{Abstract}

This article discusses a collection of theoretical and historical questions about a history of left movements and parties in Brazil. These questions come from some international currents of History like: the English Marxist Historians' Group, the Oral History, the "bistory from below", etc. In Brazil many books about the Communist Party (PCB) and the "guerrilla" have been written but there are few works about the years of 1970 and 80's - the period of the resistance and the redemocratization process. 